\title{
UMA BREVE NOTÍCIA SOBRE O LABORATÓRIO DE ESTUDOS SOBRE O IMPÉRIO ROMANO (LEIR)
}

\author{
Norberto Luiz Guarinello* \\ Fábio Faversani** \\ Recebido em: 02/04/2020 \\ Aprovado em: 27/04/2020
}

L

EIR é a sigla para Laboratório de Estudos sobre o Império Romano. Reúne dezenas de Universidades Públicas nas cinco regiões do país e foi criado em 2007. Atualmente, o LEIR se organiza em torno de cinco núcleos sediados na UFES, UFG, UFOP, Unesp e USP, que agregam professores e estudantes de cerca de vinte Universidades. Dedica-se ao propósito comum de estimular a pesquisa especializada sobre o Império Romano, o Mediterrâneo e a Antiguidade em geral. Além do intercâmbio entre pesquisadores, o Laboratório se propõe a um programa de Colóquios e publicações regulares.

O núcleo inicial do LEIR é formado por um grupo que iniciou sua colaboração à época que eram estudantes de pósgraduação do Departamento de História da USP, e que realizaram suas pesquisas tendo como tema o Império Romano, investigado sob diferentes ângulos e periodicidades. Tiveram, também, em comum o fato de pertencerem ao grupo de orientandos do Prof. Norberto Guarinello. Esses pesquisadores ingressaram em Universidades Públicas e passaram a formar novos alunos que também foram sendo integrados ao Laboratório. O LEIR é, de fato, uma duradoura prática de cooperação proveitosa entre colegas que foi, pouco a pouco, se institucionalizando. À época de sua progressiva construção, nos anos 90, o acesso a textos era muito difícil e os espaços para apresentação de trabalhos em eventos era escasso. Esses alunos, unidos por vínculos de amizade, passaram a trocar textos e se reunir para compor mesas em Congressos em que a discussão sobre a Antiguidade pudesse ser mais aprofundada. Tais iniciativas se mostraram muito proveitosas e
* Professor LivreDocente, Faculdade de Filosofia, Letras e Ciências Humanas, Universidade de São Paulo.

guarinel@usp.br

** Professor Titular, Instituto de Ciências Humanas e Sociais, Universidade Federal de Ouro Preto.

faversani@ufop.edu.br 
tiveram continuidade tanto com a formação de novas gerações quanto na cooperação entre as gerações.

O LEIR foi criado oficialmente em 2002 e, desde então, tem mudado constantemente. A sua atual coordenação é, contudo, basicamente a mesma desde a sua criação. Temos uma Coordenação Geral, ocupada por Norberto Luiz Guarinello - USP, e uma Coordenação Nacional composta por Ana Teresa Marques Gonçalves - UFG, Carlos Augusto Machado - University of St Andrews, Fábio Duarte Joly - UFOP, Fábio Faversani - UFOP, Gilvan Ventura da Silva - UFES, Margarida Maria de Carvalho - Unesp / Franca.

Além de sua coordenação, a lista de professores vinculados ao LEIR com vínculo efetivo com Instituições de Ensino Superior é a que segue:

\section{Nome do Pesquisador}

Alex Degan

Alexandre Agnolon

Artur Costrino

Belchior Monteiro Lima Neto

Camila da Silva Condilo

Deivid Valério Gaia

Dominique Santos

Edson Arantes Júnior

Érica Cristhyane Morais da Silva

Fábio Morales

Gilberto da Silva Francisco

Gustavo Junqueira

Joana Campos Clímaco

Juliana Bastos Marques

Luciane Munhoz de Omena

Lyvia Vasconcelos Baptista

Marinalva Vilar de Lima

Nathalia Monseff Junqueira

Rafael da Costa Campos

Semíramis Corsi Silva

Uiran Gebara da Silva

Thiago Eustáquio Araujo Mota

Ygor Klain Belchior

\section{Instituição em que trabalha}

Universidade Federal de Santa Catarina (UFSC)

Universidade Federal de Ouro Preto (UFOP)

Universidade Federal de Ouro Preto (UFOP)

Universidade Federal do Espírito Santo (UFES)

Universidade de Brasília (UnB)

Universidade Federal do Rio de Janeiro (UFRJ)

Universidade Regional de Blumenau (FURB)

Universidade Estadual de Goiás (UEG)

Universidade Federal do Espírito Santo (UFES)

Universidade Federal de Santa Catarina (UFSC)

Universidade Federal de São Paulo (Unifesp)

Pontifícia Universidade Católica de Campinas (PUC-Camp)

Universidade Federal do Amazonas (UFAM)

Universidade Federal do Estado do Rio de Janeiro (Unirio)

Universidade Federal de Goiás (UFG)

Universidade Federal do Rio Grande do Norte (UFRN)

Universidade Federal de Campina Grande (UFCG)

Universidade Federal do Mato Grosso do Sul (UFMS)

Universidade Federal do Pampa (Unipampa)

Universidade Federal de Santa Maria (UFSM)

Universidade Federal Rural de Pernambuco (UFRRPE)

Universidade de Pernambuco (UPE)

Universidade Estadual de Minas Gerais (UEMG) 
Além desses pesquisadores, também se vinculam ao Laboratório professores com contratos temporários com IES's, professores de outros níveis de ensino e estudantes de Mestrado, Doutorado e Iniciação Científica orientados por esses pesquisadores. No total, o LEIR congrega um número flutuante de pesquisadores, que têm estado há alguns anos sempre acima de uma centena.

O LEIR promove Colóquios Nacionais a cada dois anos, havendo rodízio entre seus núcleos para a realização dos encontros. Além disso, temos Colóquios regulares promovidos na USP, UFOP, Unesp e UFES, bem como ciclos de palestras nessas e em outras Universidades. Além disso, o LEIR, através do conjunto de seus pesquisadores, mantém uma participação regular e relevante nos Congressos da Sociedade Brasileira de Estudos Clássicos e nas reuniões do GT História Antiga, da Associação Nacional de História.

O LEIR é responsável pela publicação de duas revistas:

Mare Nostrum, publicada pela USP. https://www.revistas.usp.br/marenostrum/index

Romanitas, publicada pela UFES. http://periodicos.ufes.br/romanitas

Publica ainda uma coleção de livros, Impérios Romanos, pela UFOP, e mantém o site do LEIR nacional (https://leir.ufop.br/), onde podem ser encontradas mais informações sobre os núcleos, bem como acessados os sites que são mantidos por esses.

Por fim, em colaboração com o Núcleo de Estudos Literários da UFOP, o LEIR produz o podcast Sapere Aude, disponível na plataforma Spotify.

O Laboratório Nacional é um Grupo de Pesquisa registrado no CNPq (http:// dgp.cnpq.br/dgp/espelhogrupo/8931) e é um Grupo de Estudos da Sociedade Brasileira de Estudos Clássicos desde 11/11/2009, estando entre os primeiros a serem agregados à estrutura da SBEC.

O Laboratório de Estudos sobre o Império Romano contou em diversos momentos, e conta ainda, com o apoio de diferentes agências financiadoras, dentre as quais destacamos a CAPES, CNPq, FAPESP, FAPEMIG e FAPES, bem como das várias Universidades e Programas de Pós-Graduação a que seus pesquisadores estão vinculados. A todos esses apoiadores, manifestamos nosso reconhecimento e agradecimento. 